\title{
Survival after transapical and transfemoral aortic valve implantation: Talking about two different patient populations
}

\author{
Sabine Bleiziffer, MD, Hendrik Ruge, MD, Domenico Mazzitelli, MD, Andrea Hutter, MD, \\ Anke Opitz, MD, Robert Bauernschmitt, MD, PhD, and Rüdiger Lange, MD, $\mathrm{PhD}$
}

\begin{abstract}
Objective: Recently, suspicion had been expressed that survival might be impaired after antegrade transapical as opposed to retrograde transfemoral valve implantation in high-risk patients with aortic stenosis. We analyzed survival in patients undergoing transcatheter aortic valve implantation with special emphasis on the access site for implantation.
\end{abstract}

Methods: Between June 2007 and February 2009, 203 high-risk patients (EuroSCORE, 22\% \pm 14\%; mean age, $81 \pm 7$ years) underwent transcatheter aortic valve implantation via a transapical $(\mathrm{n}=50)$ or transfemoral $(n=153)$ access. The transapical implantation technique was chosen only in patients who had no access through diseased femoral arteries.

Results: Thirty-day survival was $88.8 \%$ after transfemoral versus $91.7 \%$ after transapical implantation $(P=.918)$. The transapical group had a significantly higher preoperative brain natriuretic peptide value and a significantly higher incidence of peripheral vessel, cerebrovascular, and coronary heart disease. Death within 30 days was valve related in 25\% (transapical) and 31\% (transfemoral), cardiac in $25 \%$ and $13 \%$, and noncardiac in $50 \%$ and $56 \%$, respectively (no significant difference). Complications specific to the access site (peripheral vessel injury or apex complications) occurred in both groups, whereas neurologic events did not occur in the transapical group $(P=.041)$.

Conclusions: Our patient and access site selection process, with the transfemoral technique considered the access site of first choice, results in comparable survival and morbidity for either transfemoral or transapical transcatheter aortic valve implantation. Both techniques are associated with certain access site-specific complications that require highly qualified management. The neurologic risk profile of the patients should be included in the decisionmaking process before transcatheter aortic valve implantation, inasmuch as neurologic events may be reduced with the transapical access.

Earn CME credits at

http://cme.ctsnetjournals.org

Since Alain Cribier and his associates ${ }^{1}$ performed the first-in-man transcatheter implantation of an aortic valve substitute in 2002, the technique has further developed and has entered the daily routine in some centers. The target population for transcatheter aortic valve implantation (TAVI) is elderly patients with several comorbidities and a consecutively increased risk for surgical aortic valve replacement (AVR) with sternotomy and cardiopulmonary bypass. ${ }^{2,3}$ Today, the main implanting routes for TAVI are the retrograde

\footnotetext{
From the Clinic for Cardiovascular Surgery, German Heart Center Munich, Munich, Germany.

Read at the Eighty-ninth Annual Meeting of The American Association for Thoracic Surgery, Boston, Massachusetts, May 9-13, 2009.

Received for publication April 23, 2009; revisions received June 22, 2009; accepted for publication July 13, 2009; available ahead of print Sept 18, 2009.

Address for reprints: Sabine Bleiziffer, MD, Clinic for Cardiovascular Surgery, German Heart Center Munich, Lazarettstr 36, 80636 Munich, Germany (E-mail: bleiziffer@dhm.mhn.de).

J Thorac Cardiovasc Surg 2009;138:1073-80

$0022-5223 / \$ 36.00$

Copyright (c) 2009 by The American Association for Thoracic Surgery

doi:10.1016/j.jtcvs.2009.07.031
}

transfemoral access and the antegrade transapical access. Inasmuch as a left anterolateral minithoracotomy is required for the transapical TAVI, this procedure is considered to be more invasive and thus may be assumed to lead to a higher incidence of mortality and morbidity. However, inasmuch as most of the implanting centers specialize in either the transfemoral or the transapical access, there are to date no comparable patient cohorts to prove or dismiss this assumption. In contrast, our basic approach to the treatment of severe aortic stenosis is to offer the most adequate treatment for the individual patient. Therefore, we established both the transarterial and the transapical implantation techniques by one team in a surgical hybrid suite. ${ }^{4}$ The present study retrospectively analyzes survivals and access site-specific complications after transfemoral versus transapical TAVI of a nonrandomized patient cohort of 203 patients.

\section{METHODS \\ Patient Selection}

Patients with high-grade symptomatic aortic stenosis who were refused for surgical AVR were evaluated for TAVI. A computed tomographic scan of the chest, abdomen, and pelvis was performed in all patients to assess the anatomy of the complete aorta and to verify the suitability of the peripheral vessels for the transfemoral access. Contraindications for transfemoral TAVI were vessel diameters less than $6.5 \mathrm{~mm}$ for CoreValve 


\section{Abbreviations and Acronyms \\ $\mathrm{AVR}=$ aortic valve replacement \\ $\mathrm{BNP}=$ brain natriuretic peptide \\ POD $=$ postoperative day \\ STS $=$ The Society of Thoracic Surgeons \\ $\mathrm{TAVI}=$ transcatheter aortic valve implantation}

prosthesis implantation (CoreValve, Inc, Irvine, Calif) or less than $7 \mathrm{~mm}$ for Edwards Sapien prosthesis implantation (Edwards Lifesciences Corporation, Irvine, Calif), severe tortuosity of the femoral or iliac arteries or the descending aorta (eg, in patients with scoliosis), or previous peripheral vessel surgery or intervention. The prosthesis type was chosen according to measurements of the aortic root anatomy (native annulus diameter, sinus height, sinus width, ascending aortic diameter) by transthoracic and transesophageal echocardiography and by computed tomography. Our policy is to consider the transfemoral site as the access of first choice. Only patients unsuitable for transfemoral TAVI underwent transapical TAVI.

\section{Prostheses and Implantation Procedure}

The CoreValve prosthesis and the Edwards Sapien prosthesis were implanted in our series. Both received the CE mark in 2007 for transarterial implantation. In addition, the Edwards Sapien prosthesis received the $\mathrm{CE}$ mark for transapical implantation in December 2007. The CoreValve prosthesis, a porcine pericardial valve mounted in a self-expandable nitinol stent, has an $18 \mathrm{~F}$ delivery sheath suitable for vessels of $6.5 \mathrm{~mm}$ or more. Transapical implantation of the CoreValve prosthesis was performed within the context of the approval study ( $\mathrm{n}=5$, approved by the institutional ethics committee). The Edwards Sapien prosthesis, a bovine pericardial valve in a balloon-expandable steel stent, is approved for both the transarterial and the transapical access. The transarterial delivery sheath is $22 \mathrm{~F}$ in size for the $23-\mathrm{mm}$ prosthesis (mean vessel size $7 \mathrm{~mm}$ ) and $24 \mathrm{~F}$ in size for the 26-mm prosthesis (mean vessel size $8 \mathrm{~mm}$ ). It is suitable for native annulus sizes of 17 to $25 \mathrm{~mm}$, whereas the CoreValve prosthesis, available in 26- and 29-mm sizes, may be implanted in annuli of 19 to $27 \mathrm{~mm}$.

All patients were operated on in a surgical hybrid suite. We opted to perform the procedures with the patients under general anesthesia to assure stable hemodynamics and to avoid patient movements during valve implantation. Transfemoral valve implantation was performed by percutaneous puncture and device closure (ProStar XL; Abbott Vascular, Abbott Park, Ill; $n=89)$ or by surgical dissection of the femoral artery $(n=64)$. Antegrade transapical aortic valve implantation was performed through a left anterolateral minithoracotomy. A transient pacemaker wire was placed transvenously for transarterial retrograde implantation and epicardially for transapical antegrade valve implantation. A balloon valvuloplasty of the stenotic aortic valve was performed under rapid ventricular pacing at 160 to 180 beats/min in all patients. Under fluoroscopic control, the prosthesis, crimped on the delivery catheter, was placed in the aortic annulus. The CoreValve prosthesis was then released stepwise on the beating heart, whereas the Edwards Sapien prosthesis was deployed by balloon inflation under rapid ventricular pacing. Details of the implantation procedures have previously been described. ${ }^{5-8}$ Prosthesis function was assessed by angiography and intraoperative transesophageal echocardiographic investigation. In patients with a lateral minithoracotomy, a chest tube was placed before wound closure. After the procedure, the patients were transferred to the intensive care unit and usually extubated within 2 to 4 hours.

\section{Patients}

All patients signed an informed consent form. The study was approved by the local ethics committee (2234/08). Of 215 patients who underwent TAVI between June 2007 and February 2009, twelve were excluded from this study. Nine had neither transfemoral nor transapical TAVI (TAVI via the subclavian artery, $\mathrm{n}=5$; TAVI through ascending aorta via ministernotomy, $\mathrm{n}=4$ ), and in 3 patients the implantation was not successful (conversion to surgery, $\mathrm{n}=1$; procedure aborted, $\mathrm{n}=1$; supra-annular displacement of a CoreValve prosthesis and later surgical AVR, $n=1$ ). Among the study group of 203 patients, 153 underwent transfemoral TAVI (Edwards Sapien prosthesis, $\mathrm{n}=4$; CoreValve prosthesis, $\mathrm{n}=149$ ) and 50 underwent transapical TAVI (Edwards Sapien prosthesis, $\mathrm{n}=45$; CoreValve prosthesis, $\mathrm{n}=5$ ). The patient characteristics are summarized in Table 1. In the transapical group, the number of female patients, the preoperative brain natriuretic peptide (BNP) level, and the incidence of vascular (coronary, cerebrovascular, and peripheral vessel) diseases were significantly higher. Furthermore, the femoral vessel diameter was significantly smaller, and severe kinking of the descending aorta of the iliac or femoral arteries was more frequent.

\section{Data Collection and Statistical Analysis}

Patients' demographic data, operative data, and postoperative complications were recorded in a computerized database. Our standard protocol includes a telephone interview 30 days postoperatively and an echocardiographic investigation 6 months after TAVI. The self-assessed health state was obtained with the question: "How is your general health state on a scale of $0 \%$ to $100 \%$ ?" The causes of death were classified according to the guidelines for reporting mortality and morbidity after cardiac valve interventions. ${ }^{9}$ Descriptive data for continuous variables are presented as means \pm standard deviation. Categorical variables are presented as relative frequencies. Fisher's exact test was performed to detect significant differences between groups. For comparison of continuous variables between 2 groups, the $t$ test was used (2-tailed tests were used for all analyses). The survival function was illustrated by Kaplan-Meier curves. Survival distributions were compared with the log-rank test.

\section{RESULTS \\ Intraoperative Data}

The duration of the procedure was significantly longer for transapical TAVI. However, the amount of contrast agent needed, the exposure time to radiation, and the dose-area product were significantly less with transapical TAVI (Table 2). In contrast, intraprocedural cardiac depression with the need for catecholamine therapy, cardiopulmonary resuscitation, or cardiopulmonary bypass occurred more frequently during transapical TAVI (no significant difference).

\section{Access Site Complications}

The incidence, treatment, and sequelae of access site complications are summarized in Table 3.

\section{Neurologic Events}

The overall incidence of neurologic events was $11(7 \%)$ of 153 after transfemoral TAVI versus $0 \%$ after transapical TAVI $(P=.041)$. Six patients did not awaken. In 3 of those, major cerebral bleeding was diagnosed after transfemoral CoreValve implantation, which is performed under platelet aggregation inhibition with clopidogrel and aspirin. Four patients had cerebral media infarction with persistent hemiparesis $(n=3)$ or arm paresis $(n=1)$. The patient with arm paresis recovered with minor residual effects. One patient had a transitory ischemic attack without a residual effect. 
TABLE 1. Preoperative patient characteristics

\begin{tabular}{|c|c|c|c|}
\hline Parameter & $\begin{array}{c}\text { Transfemoral } \\
\text { TAVI } \\
(\mathbf{n}=\mathbf{1 5 3})\end{array}$ & $\begin{array}{c}\text { Transapical } \\
\text { TAVI } \\
(\mathbf{n}=\mathbf{5 0})\end{array}$ & $\begin{array}{c}P \\
\text { value }\end{array}$ \\
\hline Age (y) & $81.4 \pm 6.7$ & $81.5 \pm 5.9$ & .946 \\
\hline Female gender (n) & $80 / 153(52 \%)$ & $39 / 50(78 \%)$ & $.001 *$ \\
\hline Logistic EuroSCORE (\%) & $22.1 \pm 13.6$ & $22.0 \pm 14.9$ & .972 \\
\hline STS score $(\%)$ & $6.5 \pm 4.1$ & $6.3 \pm 3.8$ & .786 \\
\hline NYHA class & $3.1 \pm 0.3$ & $3.1 \pm 0.2$ & .075 \\
\hline Self-assessed hea & $52.7 \pm 18.0$ & $47.7 \pm 19.8$ & .160 \\
\hline Preoperative BNP val & $6157 \pm 7956$ & $12472 \pm 28722$ & .025 \\
\hline $\begin{array}{l}\text { Preoperative valve orifice } \\
\text { area }\left(\mathrm{cm}^{2}\right)\end{array}$ & $0.66 \pm 0.2$ & $0.58 \pm 0.2$ & .019 \\
\hline Coronary heart disease & $78 / 153(51 \%)$ & $33 / 50(66 \%)$ & .045 \\
\hline Previous PT & $28 / 153(18 \%)$ & $14 / 50(28 \%)$ & \\
\hline Previous coronary & $25 / 153(16 \%)$ & $9 / 50(18 \%)$ & \\
\hline Peripheral vessel disease & $26 / 153(17 \%)$ & $26 / 50(52 \%)$ & $<.001$ \\
\hline Cerebrovascular disease & $24 / 153(16 \%)$ & $16 / 50(32 \%)$ & 012 \\
\hline Previous stroke & $17 / 153(11 \%)$ & $4 / 50(8 \%)$ & .362 \\
\hline Previous cardiac surgery & $28 / 153(18 \%)$ & $11 / 50(22 \%)$ & .349 \\
\hline $\begin{array}{l}\text { High-grade atrioventricular } \\
\text { valve lesion }\end{array}$ & $32 / 153(21 \%)$ & $8 / 50(16 \%)$ & .295 \\
\hline COPD & $35 / 153(23 \%)$ & $6 / 50(12 \%)$ & .096 \\
\hline Pulmonary hypertension & $34 / 153(22 \%)$ & $14 / 50(28 \%)$ & .257 \\
\hline Renal insufficiency & $31 / 153(20 \%)$ & $10 / 50(20 \%)$ & .573 \\
\hline Ejection fraction $<50 \%$ & $64 / 153(42 \%)$ & $17 / 50(34 \%)$ & .208 \\
\hline \multicolumn{4}{|l|}{ Femoral artery diameter $(\mathrm{mm})$} \\
\hline & $8.0 \pm 1.1$ & $7.0 \pm 1.0$ & $<.001$ \\
\hline Left & $8.1 \pm 1.0$ & $7.1 \pm 1.1$ & $<.001$ \\
\hline Kinking of descending aorta & $5 / 153(3 \%)$ & $6 / 50(12 \%)$ & .028 \\
\hline
\end{tabular}

$B N P$, Brain natriuretic peptide; $C O P D$, chronic obstructive pulmonary disease, $N Y H A$, New York Heart Association, $P T C A$, percutaneous transluminal coronary angioplasty; STS, Society of Thoracic Surgeons; TAVI, transcatheter aortic valve implantation. *Boldface $P$ values indicate statistical significance.

\section{Survival and Clinical State of the Patients}

Thirty-day and 6-month survivals were $88.8 \%$ and $80.1 \%$, respectively, after transfemoral TAVI and $91.7 \%$ and $73.4 \%$, respectively, after transapical TAVI $(P=$ .918 , Figure 1). There were no further deaths later than 6 months postoperatively.

The causes of death were not different between the 2 groups. Death within 30 days was valve related in $25 \%$ (1/4) (transapical access) and 29\% (5/17) (transfemoral access), cardiac in $25 \%(1 / 4)$ and $12 \%(2 / 17)$, and noncardiac in $50 \%(2 / 4)$ and $59 \%(9 / 17)$, respectively $(P=.793)$. Death later than 30 days postoperatively was valve related in 25\% (1/4) (transapical access) and 36\% (4/11) (transfemoral access) and noncardiac in 75\% (3/4) and 64\% (7/ $11)$, respectively $(P=.680)$.

Mean New York Heart Association class of the survivors after TAVI improved from $3.1 \pm 0.3$ (transfemoral TAVI) and $3.1 \pm 0.2$ (transapical TAVI) to $1.7 \pm 0.6$ and $1.6 \pm 0.6$ at 30 days, respectively, and to $1.8 \pm 0.6$ and $1.7 \pm 0.4$ at 6 months, respectively $(P<.001$, Figure $2, A)$. The self-assessed health state improved from $52 \% \pm 18 \%$ (transfemoral TAVI) and $48 \% \pm 20 \%$ (transapical TAVI) to $67 \% \pm 17 \%$ and $69 \%$
TABLE 2. Intraoperative data

\begin{tabular}{lccr}
\hline \multicolumn{1}{c}{ Parameter } & $\begin{array}{c}\text { Transfemoral } \\
\text { TAVI }(\mathbf{n}=\mathbf{1 5 3})\end{array}$ & $\begin{array}{c}\text { Transapical } \\
\text { TAVI }(\mathbf{n}=\mathbf{5 0})\end{array}$ & $\boldsymbol{P}$ value \\
\hline Contrast agent $(\mathrm{mL})$ & $152 \pm 65$ & $116 \pm 50$ & $<. \mathbf{0 0 1}$ \\
Fluoroscopy time $(\mathrm{min})$ & $26.6 \pm 9.9$ & $14.8 \pm 9.6$ & $<. \mathbf{0 0 1}$ \\
$\begin{array}{l}\text { Dose-area-product } \\
\quad\left(\mu \mathrm{Gy} \cdot \mathrm{cm}^{2}\right)\end{array}$ & $29,927 \pm 18,349$ & $19,580 \pm 18,049$ & $\mathbf{. 0 0 1}$ \\
$\begin{array}{l}\text { Procedure time (min) } \\
\text { Intraprocedural cardiac }\end{array}$ & $76.4 \pm 34.4$ & $95.4 \pm 26.1$ & $<. \mathbf{0 0 1}$ \\
$\quad$ depression & & & .086 \\
\hline
\end{tabular}

TAVI, Transcatheter aortic valve implantation.

$\pm 14 \%$ at 30 days, respectively, and to $64 \% \pm 20 \%$ and $66 \%$ $\pm 17 \%$ at 6 months, respectively $(P<.001$, Figure $2, B)$.

\section{Outcome of the Patients Excluded from this Study}

Of 5 patients undergoing TAVI through the subclavian artery, 1 died on postoperative day (POD) 69 of esophageal varicosis bleeding and 4 are alive at latest follow-up. Among 4 patients with an ascending aortic approach, 1 had aortic root rupture and died on POD 1, and another patient died on POD 25 of acute intrathoracic bleeding. The remaining 2 patients are alive at latest follow-up. In 3 patients, the TAVI procedure was not successful. In 1 patient, emergency conversion to surgical AVR was required after aortic root rupture during transapical implantation of a Sapien prosthesis. Multiorgan failure developed, and the patient died on POD 2. In another patient, a transfemorally deployed CoreValve prosthesis was dislocated above the coronary arteries and could not be retrieved adequately into the ascending aorta to implant a second valve. This patient underwent conventional AVR 1 week later. She had a prolonged stay in the intensive care unit and was discharged on POD 50. In a third patient, treatment of high-grade homograft regurgitation with a transfemoral CoreValve implantation was planned as a bailout procedure after repeated redo operations. Owing to the regurgitation, it was impossible to stabilize the partially deployed valve in the aortic annulus despite rapid pacing. The prosthesis was removed from the patient and the procedure was aborted. The patient underwent successful surgical redo AVR later.

\section{DISCUSSION}

There is ongoing debate concerning whether the transfemoral or the transapical access for TAVI is superior. On the one hand, transapical TAVI is considered to be more invasive with an anterolateral minithoracotomy and left ventricular puncture; on the other hand, manipulations in the aortic arch associated with the transfemoral access are completely avoided. Inasmuch as the centers offering TAVI usually specialize in either the transfemoral or the transapical access, depending on whether the specialization is cardiologic or surgical, comparisons of the results of those independent series are questionable. We present for the first 
TABLE 3. Access site-specific complications

\begin{tabular}{|c|c|c|}
\hline Type of complication & Therapy & Sequelae \\
\hline \multicolumn{3}{|l|}{ Transfemoral TAVI } \\
\hline $\begin{array}{l}\text { Femoral vessel complication }(\mathrm{n}=24 / 153,16 \%) \\
\begin{aligned} \mathrm{n} & =7 \text { clinically relevant hematoma of the groin } \\
\mathrm{n} & =12 \text { femoral vessel rupture } \\
\mathrm{n} & =2 \text { vessel thrombosis } \\
\mathrm{n} & =2 \text { vessel occlusion or false aneurysm }\end{aligned}\end{array}$ & $\begin{array}{l}\mathrm{n}=1 \text { manual compression } \\
\mathrm{n}=2 \text { stent implantation } \\
\mathrm{n}=21 \text { surgical therapy }(\mathrm{n}=15 \text { surgical } \\
\\
\text { suture or patch, } \mathrm{n}=5 \text { insertion of a vascular } \\
\text { prosthesis, } \mathrm{n}=1 \text { hematoma revision) }\end{array}$ & $\begin{array}{l}3 / 24 \text { patients died of sequelae of } \\
\text { femoral access site complication }\end{array}$ \\
\hline Wound infection $(\mathrm{n}=1 / 153,0.7 \%)$ & Conservative treatment, antibiotics & Resolved without residuals \\
\hline \multicolumn{3}{|l|}{ Transapical TAVI } \\
\hline Postprocedural bleeding $(\mathrm{n}=5 / 50,10 \%)$ & $\begin{array}{l}\text { Surgical re-exploration (only one of those was } \\
\text { bleeding from the left ventricular apex) }\end{array}$ & Resolved without residuals \\
\hline Left ventricular aneurysm $(n=1 / 50,2 \%)$ & Surgical revision 2 months after the initial procedure & Patient died \\
\hline Secondary wound healing $(\mathrm{n}=2 / 50,4 \%)$ & Vacuum therapy and later wound closure & Resolved without residuals \\
\hline $\begin{array}{l}\text { New hypokinesia or akinesia of the apex }(n=4 / 13) \\
\text { at echocardiographic 6-month follow-up }\end{array}$ & No therapy & Long-term impact not known \\
\hline
\end{tabular}

TAVI, Transcatheter aortic valve implantation.

time a comparative analysis of 203 consecutive patients who underwent TAVI via a transfemoral or a transapical approach by the same team in a surgical hybrid suite.

With the opportunity to offer all kinds of interventional and surgical treatment for aortic stenosis, ${ }^{4}$ we aim to choose the most appropriate access for the individual patient. Only patients at high risk for surgical AVR were evaluated for TAVI. High risk for surgery was assessed clinically, supported by the assessment of the EuroSCORE, the Society of Thoracic Surgeons (STS) score (according to the statement papers of the European Association of CardioThoracic Surgery [EACTS] and the European Society of Cardiology [ESC], and the European Association of Percutaneous Cardiovascular Interventions $[\mathrm{EAPCI}],{ }^{3}$ and the American Heart Association ${ }^{2}$ ). All patients were screened

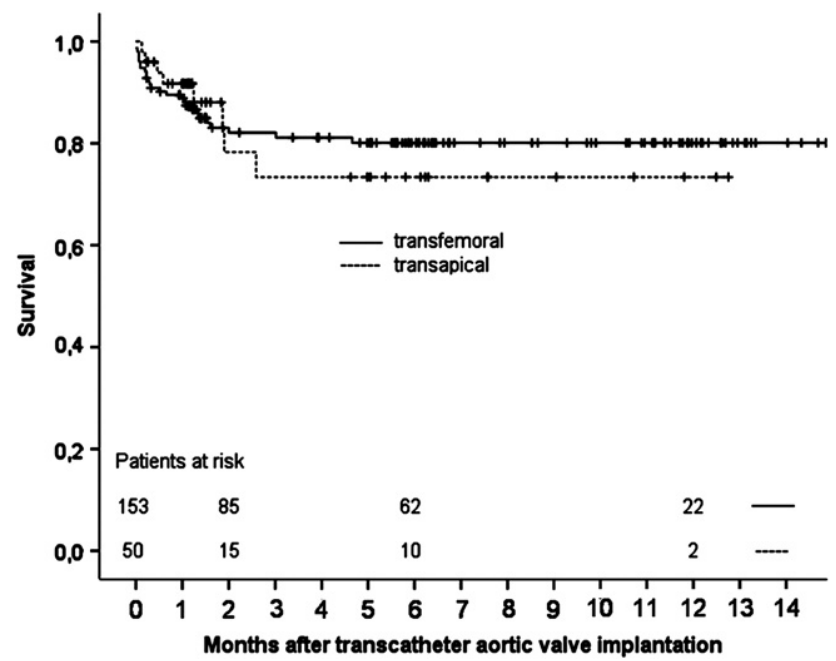

FIGURE 1. Survival curve for 203 patients after transcatheter aortic valve implantation. Follow-up duration is shown in months on the $\mathrm{x}$-axis. Thirtyday and 6-month survivals were $88.8 \%$ and $80.1 \%$ after transfemoral transcatheter aortic valve implantation (TAVI) (black line) and $91.7 \%$ and $73.4 \%$ after transapical TAVI (dotted line) $(P=.918)$. for transfemoral TAVI first. Our data show that up to $28 \%$ of the patients exhibit contraindications for the transfemoral access. In those, the subclavian artery is evaluated as the access site of second choice. Inasmuch as most patients with peripheral vessel disease also have severely diseased subclavian arteries, this access was suitable for only 5 patients. ${ }^{10}$ The remaining patients usually underwent transapical TAVI, except for 4 "no-access" patients who underwent TAVI through the ascending aorta. ${ }^{11}$

According to our decision algorithm, our patient populations undergoing transfemoral or transapical TAVI exhibit different comorbidities. The increased incidence of peripheral vascular disease in patients undergoing transapical TAVI reflects the contraindications for femoral access. Additionally, those patients have a high coincidence of coronary artery and cerebrovascular disease. The higher number of female patients in the transapical group may be explained by the fact that the Edwards Sapien prosthesis, which was implanted in most patients with transapical access (except for 5 patients with transapical CoreValve implantation within the context of the approval study ${ }^{6}$ ), is limited to a maximum aortic annulus diameter of 24.5 $\mathrm{mm}$. In the transapical group, the BNP serum level was also significantly higher than in the transfemoral group. BNP serves as a biological marker for heart failure and may indicate increased myocardial stress. We presume that the differences among the groups might have increased the risk for the transapical group, although the EuroScore and STS score do not display this difference.

Despite the differences between the groups, survival was not related to the implantation technique $(P=.918$, see survival curve, Figure 1). Thirty-day mortality after transfemoral TAVI is reported to be $0 \%$ to $25 \%$ in small series of 10 to 50 patients. ${ }^{8,12-17}$ In a larger series of 102 patients, 30-day mortality was $10.8 \%,{ }^{18}$ which is similar to our data of $11.2 \%$. Thirty-day mortality after transapical TAVI is reported to be $8 \%$ to $23 \%$ in the literature with series of 26 to 59 

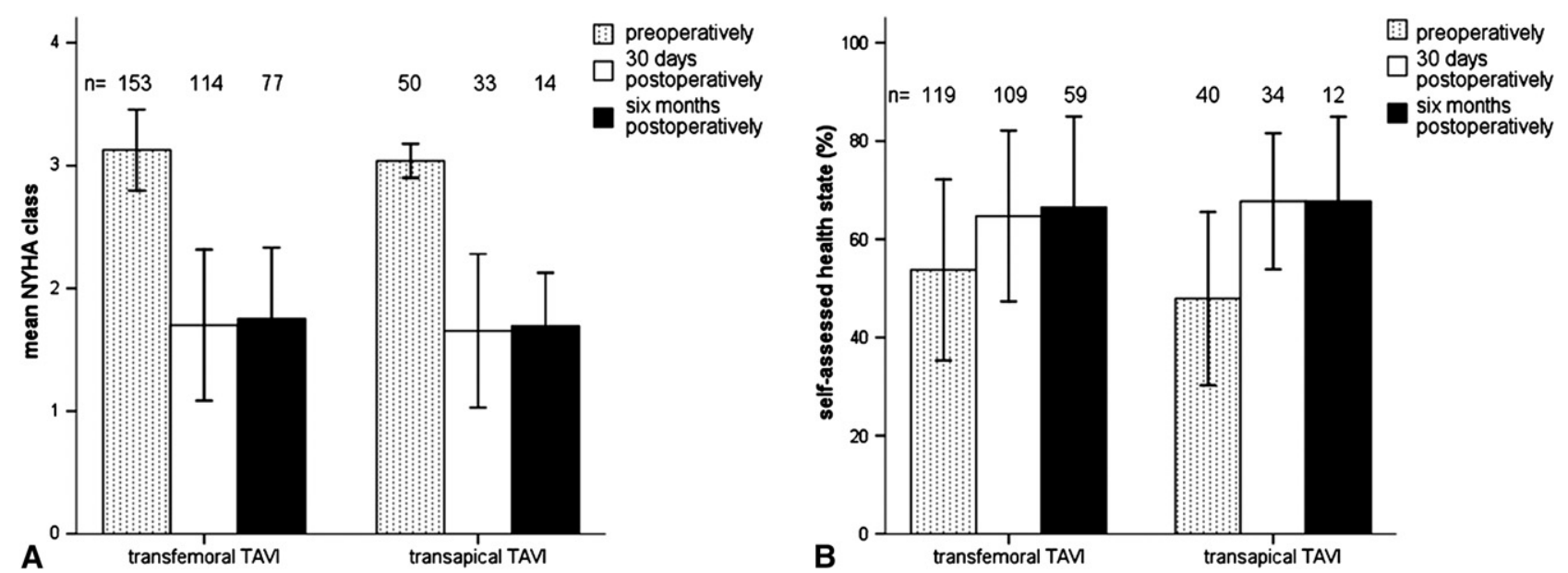

FIGURE 2. A, Mean New York Heart Association (NYHA) classification preoperatively (dotted bars), at 30 days postoperatively (white bars), and at 6 months postoperatively (black bars) of patients undergoing transfemoral or transapical transcatheter aortic valve implantation (TAVI). B, Self-assessed health state, in percent, preoperatively (dotted bars), at 30 days postoperatively (white bars), and at 6 months postoperatively (black bars) of patients undergoing transfemoral or transapical TAVI. The self-assessed health state was obtained with the question: "How is your general health state on a scale of $0 \%$ to $100 \%$ ?"

patients, ${ }^{7,19-22}$ compared with $8.3 \%$ in our series. Six-month survival data are limited and range from $75 \%$ to $84 \% 14,17,18$ after transfemoral TAVI (80.1\% in our series) and from $74 \%$ to $85 \%^{7,20,21}$ after transapical TAVI (73.4\% in our series). The deaths occurred within the first 4 months in all series. In 11 of 14 patients who died within 4 months in our series, death has to be considered a sequela of the procedure even if not valve related, inasmuch as those patients did not recover from the procedure and could not be discharged from the hospital. We did not see differences between transfemoral and transapical TAVI concerning the cause of death, which was noncardiac in $50 \%$ to $75 \%$ (eg, intestinal bleeding or pneumonia and sepsis). We conclude from our data that TAVI can be performed through either access with comparable procedural and midterm survival, despite the assumption that patients requiring transapical TAVI might have been at higher risk for the intervention. In our opinion, the results are related to the choice of the most appropriate access site for the individual patient. The most informed and unbiased decision of the appropriate access can be made by a team mastering both the transfemoral and the transapical TAVI, as well as conventional surgical AVR.

Despite comparable survival data, there are complications specific to the retrograde and the antegrade accesses. Peripheral vessel rupture, occlusion, or bleeding necessitating interventional or surgical treatment occurred in $16 \%$ of the 153 transfemorally treated patients in our patient population and is described in $9 \%$ to $20 \%$ of the cases by other groups $^{8,12,14-17}$ with population sizes of only 10 to 50 patients. Immediate surgical or interventional treatment is mandatory if these complications occur, because blood loss of a certain extent is not tolerated by these frail patients. A variety of complications are associated with the transapical ac- cess. Re-exploration for postoperative thoracic bleeding was necessary in $10 \%$, although in only 1 of those cases was the bleeding from the apical puncture site. The frequency of reexploration for bleeding was $8 \%$ to $14 \%$ in previous reports. ${ }^{7,21,22}$ The development of a left ventricular false aneurysm is a rare but serious complication, which occurred in 1 of our patients. Another group also reported an individual case. $^{23}$ There are no data on long-term impairment of the left ventricular apex after puncture for TAVI. Preliminary echocardiographic 6-month follow-up data from 13 patients in our series showed new hypokinesia or akinesia of the apex in 4 of 13 patients. The impact of these findings is subject to further investigation in a larger cohort. In summary, acute access site complications of either transfemoral or transapical TAVI are potentially life-threatening and require highly qualified interventional or surgical treatment.

Besides complications at the access site, there were further intraprocedural differences between transfemoral and transapical TAVI. As valve positioning proceeds more promptly with the shorter distance during transapical TAVI and no angiograms of the iliac or femoral arteries are necessary, exposure to radiation and the amount of contrast agent is significantly reduced. However, we could not demonstrate a reduction of postprocedural renal failure with the transapical access: creatinine level increased by $1.0 \mathrm{mg} / \mathrm{dL}$ in $16(10 \%)$ of 153 patients after transfemoral TAVI and in $5(10 \%)$ of 50 patients after transapical TAVI $(P=.881)$; need for dialysis occurred in $13(8 \%)$ of 153 after transfemoral TAVI and in $4(8 \%)$ of 50 after transapical TAVI $(P=.912)$. Furthermore, intraprocedural cardiac depression with the need for catecholamine therapy, cardiopulmonary resuscitation, or cardiopulmonary bypass occurred more frequently during transapical TAVI 
(no significant difference, Table 2), which may reflect a more unstable condition of the patients requiring transapical TAVI, conceivably induced by the thoracotomy and deeper anesthesia.

There is evidence that the incidence of neurologic events is reduced with the transapical TAVI technique. The reported rates of neurologic events after transapical TAVI are $0 \%$ to $5 \%^{7,9-22}$ in the literature and $0 \%$ in our cohort, whereas stroke rates are $0 \%$ to $20 \%{ }^{12,14,15,17,8}$ in patients undergoing transfemoral TAVI. This phenomenon might be explained by the avoidance of manipulation in a calcified aortic arch with the transapical technique. The rate of embolic neurologic events that might be attributed to passage of the aortic arch during transfemoral TAVI was 5\% (8/ 153 ) in our series, whereas 3 patients had intracerebral bleeding, which is a complication related to double platelet inhibition. However, there were no neurologic events with the transapical approach $(P=.041)$. On the basis of these observations, patients at high risk for neurologic events should be forwarded for transapical TAVI.

With the introduction of a new technique, some of the mortality and morbidity after TAVI might be attributed to a learning curve. However, analysis of our current data does not reveal a decrease of mortality or complications over time except for the 30-day survival in our first series of transapical TAVI $(\mathrm{n}=27,30$-day survival $79.1 \%$, no significant difference).

Concerning the recovery and clinical state after TAVI, measured by the New York Heart Association classification and by the self-assessed health state, we did not see differences between transfemoral and transapical TAVI (Figure 2). The survivors of both groups demonstrated a remarkable improvement in their clinical state.

\section{CONCLUSION}

After gaining experience with more than 200 patients undergoing TAVI, we state that our patient and access site selection process, with the transfemoral technique considered the access site of first choice, results in comparable survival and morbidity for either transfemoral or transapical TAVI. The need to open the thorax through a lateral minithoracotomy alone cannot be blamed for impaired survival seen in some series after transapical TAVI. Both techniques are associated with certain access site-specific complications that require highly qualified management. Modifications of our decision-making process will depend on further long-term data. At this stage, the neurologic risk profile of the patients was included as a major criterion for the transapical approach, because neurologic events may be reduced.

\section{Limitations}

Using two different valve systems (CoreValve mainly but not exclusively for the transfemoral approach and Edwards
Sapien mainly but not exclusively for the transapical approach), we cannot rule out that biases might have been introduced.

\section{References}

1. Cribier A, Eltchaninoff H, Bash A, Borenstein N, Tron C, Bauer F, et al. Percutaneous transcatheter implantation of an aortic valve prosthesis for calcific aortic stenosis: first human case description. Circulation. 2002;106:3006-8.

2. Rosengart TK, Feldman T, Borger MA, Vassiliades TA Jr, Gillinov AM, Hoercher KJ, et al. Percutaneous and minimally invasive valve procedures: a scientific statement from the American Heart Association Council on Cardiovascular Surgery and Anesthesia, Council on Clinical Cardiology, Functional Genomics and Translational Biology Interdisciplinary Working Group, and Quality of Care and Outcomes Research Interdisciplinary Working Group. Circulation. 2008; 117:1750-67.

3. Vahanian A, Alfieri O, Al-Attar N, Antunes M, Bax J, Cormier B, et al. Transcatheter valve implantation for patients with aortic stenosis: a position statement from the European Association of Cardio-Thoracic Surgery (EACTS) and the European Society of Cardiology (ESC), in collaboration with the European Association of Percutaneous Cardiovascular Interventions (EAPCI). Eur Heart J. 2008; 29:1463-70.

4. Bleiziffer S, Ruge H, Mazzitelli D, Schreiber C, Hutter A, Laborde JC, et al. Results of percutaneous and transapical transcatheter aortic valve implantation performed by a surgical team. Eur J Cardiothorac Surg. 2009;35:615-20.

5. Grube E, Schuler G, Buellesfeld L, Gerckens U, Linke A, Wenaweser P, et al. Percutaneous aortic valve replacement for severe aortic stenosis in high-risk patients using the second- and current third-generation self-expanding CoreValve prosthesis: device success and 30-day clinical outcome. J Am Coll Cardiol. 2007;50:69-76.

6. Lange R, Schreiber C, Gotz W, Hettich I, Will A, Libera P, et al. First successful transapical aortic valve implantation with the Corevalve Revalving system: a case report. Heart Surg Forum. 2007;10:E478-9.

7. Walther T, Simon P, Dewey T, Wimmer-Greinecker G, Falk V, Kasimir MT, et al. Transapical minimally invasive aortic valve implantation: multicenter experience. Circulation. 2007;116(11 Suppl):I240-5.

8. Webb JG, Chandavimol M, Thompson CR, Ricci DR, Carere RG, Munt BI, et al. Percutaneous aortic valve implantation retrograde from the femoral artery. Circulation. 2006;113:842-50.

9. Akins CW, Miller DC, Turina MI, Kouchoukos NT, Blackstone EH, Grunkemeier GL, et al. Guidelines for reporting mortality and morbidity after cardiac valve interventions. Eur J Cardiothorac Surg. 2008;33:523-8.

10. Ruge H, Lange R, Bleiziffer S, Hutter A, Mazzitelli D, Will A, et al. First successful aortic valve implantation with the CoreValve ReValving System via a right subclavian artery access: a case report. Heart Surgery Forum. 2008;11:E323-4.

11. Bauernschmitt R, Schreiber C, Bleiziffer S, Ruge H, Mazzitelli D, Hutter A, et al. Transcatheter aortic valve implantation through the ascending aorta: an alternative option for no-access patients. Heart Surg Forum. 2009;12:E63-4.

12. Berry C, Asgar A, Lamarche Y, Marcheix B, Couture P, Basmadjian A, et al. Novel therapeutic aspects of percutaneous aortic valve replacement with the $21 \mathrm{~F}$ CoreValve Revalving System. Catheter Cardiovasc Interv. 2007;70: 610-6.

13. Cribier A, Eltchaninoff H, Tron C, Bauer F, Agatiello C, Nercolini D, et al. Treatment of calcific aortic stenosis with the percutaneous heart valve: mid-term follow-up from the initial feasibility studies: the French experience. $J$ Am Coll Cardiol. 2006;47:1214-23.

14. Descoutures F, Himbert D, Lepage L, Iung B, Detaint D, Tchetche D, et al. Contemporary surgical or percutaneous management of severe aortic stenosis in the elderly. Eur Heart J. 2008;29:1410-7.

15. Marcheix B, Lamarche Y, Berry C, Asgar A, Laborde JC, Basmadjian A, et al. Surgical aspects of endovascular retrograde implantation of the aortic CoreValve bioprosthesis in high-risk older patients with severe symptomatic aortic stenosis. J Thorac Cardiovasc Surg. 2007;134:1150-6.

16. Spargias K, Manginas A, Pavlides G, Khoury M, Stavridis G, Rellia P, et al. Transcatheter aortic valve implantation: first Greek experience. Hellenic J Cardiol. 2008;49:397-407.

17. Webb JG, Pasupati S, Humphries K, Thompson C, Altwegg L, Moss R, et al. Percutaneous transarterial aortic valve replacement in selected high-risk patients with aortic stenosis. Circulation. 2007;116:755-63.

18. Grube E, Buellesfeld L, Mueller R, Saueren B, Zickmann B, Nair D, et al. Progress and current status of percutaneous aortic valve replacement: results of three 
device generations of the CoreValve Revalving System. Circ Cardiovasc Intervent. 2008; 1:167-75.

19. Svensson LG, Dewey T, Kapadia S, Roselli EE, Stewart A, Williams M, et al. United States feasibility study of transcatheter insertion of a stented aortic valve by the left ventricular apex. Ann Thorac Surg. 2008;86:46-54.

20. Walther T, Falk V, Kempfert J, Borger MA, Fassl J, Chu MW, et al. Transapical minimally invasive aortic valve implantation; the initial 50 patients. Eur J Cardiothorac Surg. 2008;33:983-8.

21. Ye J, Cheung A, Lichtenstein SV, Altwegg LA, Wong DR, Carere RG, et al. Transapical transcatheter aortic valve implantation: 1-year outcome in 26 patients. J Thorac Cardiovasc Surg. 2009;137:167-73.

22. Zierer A, Wimmer-Greinecker G, Martens S, Moritz A, Doss M. The transapical approach for aortic valve implantation. J Thorac Cardiovasc Surg. 2008;136: 948-53.

23. Al-Attar N, Raffoul R, Himbert D, Brochet E, Vahanian A, Nataf P. False aneurysm after transapical aortic valve implantation. J Thorac Cardiovasc Surg. 2009; 137:e21-2.

\section{Discussion}

Dr Michael Mack (Dallas, Tex). My disclosure is that I am on the Executive Committee of the PARTNER Trial of the Edwards Sapien valve in the United States.

Dr Bleiziffer and the team from Munich have presented their results in just over 200 patients undergoing TAVI, with approximately $75 \%$ of the procedures being performed by a transfemoral and $25 \%$ by a transapical approach. Their analysis compares two different access approaches and concludes that transapical outcomes are adversely affected by patient selection factors such as female gender, peripheral vascular disease, cerebrovascular disease, and coronary artery disease. Although I substantially agree with this assessment, the analysis is somewhat confounded by the fact that two different valve systems were used: the CoreValve primarily but not exclusively for the transfemoral approach and the Edwards valve primarily but not exclusively for the transapical approach. I am also concerned that this was not an intent-to-treat analysis and at least 3 patients with aborted procedures or conversions were not included in the analysis.

Dr Bleiziffer, I would like to highlight some key points of your series and ask 3 questions.

First, the 30-day survival was approximately the same in both access approaches, at about $90 \%$, yet the 6-month survival is only $80 \%$ after transfemoral and $73 \%$ after transapical. What happened to these patients between 30 days and 6 months, especially the transapical patients? Is this a patient selection issue or a comment on the invasive nature of the procedure? I would have expected the survival curves to be relatively flat after 30 days, but they do not flatten out until 6 months.

Dr Bleiziffer. As I mentioned, most of the patients died within 3 months and all deaths were indeed related to the procedure. They had a long intensive care unit stay and died of sequelae of the procedure. The fact that the transapical curve goes down a little more is explained because some deaths occurred right in the beginning among our transapical group.

Dr Mack. Second, the stroke rate is of some concern, being 7\% in the transfemoral and zero in the transapical group. As Dr Bavaria showed at the Adult Cardiac Postgraduate Course yesterday, in a small group of patients undergoing the transfemoral approach with the Edwards system, transcranial Doppler high-intensity transient signals indicating cerebral emboli occur most frequently with the passage of the valve across the arch, second with traverse of the wire across the arch, and least with valve deployment and balloon valvuloplasty. Do you therefore consider atherosclerotic disease of the aortic arch and the ascending aorta yet another "access issue," and how do you screen for it before deciding on the approach? Does everybody get a computed tomographic scan to assess the $\operatorname{arch}$ ?

Dr Bleiziffer. Every single patient undergoes a computed tomographic scan of the thorax, abdomen, and pelvis for identification of the calcifications and anatomy of the root and of the peripheral vessels. At present, the type of calcifications in the arch does not influence our decision for a transfemoral or a transapical implantation. And not all of the neurologic events were embolic. Some were intracerebral bleedings. These might not be related to the passage of the aortic arch.

Dr Mack. My third question relates to the transfemoral-first approach that you use, as do most programs. With roughly equivalent results between the two approaches, with the results for stroke better with the transapical approach, and with your study showing that the transapical approach was disadvantaged by patient selection, why don't you adopt a transapical-first approach like programs in Leipzig and Laval? At the minimum, it seems to me, you have the basis for an all-comer randomized trial between the two approaches.

Dr Bleiziffer. I did not really understand the question. Could you repeat it?

Dr Mack. Your approach is a transfemoral-first approach.

Dr Bleiziffer. Yes.

Dr Mack. The outcomes appear to be the same, yet there seems to be an advantage for transapical from a stroke standpoint. Why not do a transapical approach first and then the transfemoral in those in whom transapical is contraindicated, such as severe chronic lung disease, or why not randomize between the two approaches?

Dr Bleiziffer. Our decision tree is evolving and will develop depending on our long-term results. We confirm our data and adjust the decision tree at some intervals.

Dr Mack. My suggestion is that you have enough data now to reassess that decision tree.

Dr Bleiziffer. We do not know about the long-term sequelae of the apical approach, as I mentioned before, so there are advantages and disadvantages of both approaches.

Dr Mack. This seem like a perfect time for a randomized trial.

Dr Joseph E. Bavaria (Philadelphia, Pa). I want to congratulate this group on being one of the pre-eminent surgical groups in the world doing transcatheter valve procedures. They are a surgical group that uses both transfemoral and transapical approaches and actually uses any appropriate access, such as transsubclavian, transiliac, transaortic, whatever. This allows them to be completely free of conflict of interest. It is a fantastic group.

I would also like to confirm what Michael Mack just said about the concept of the transapical-first selection tree as opposed to the transfemoral-first selection tree. That might be very interesting. I know there are many groups in Europe that are doing that.

My questions really relate to your learning curve issues. If you were to take out the first 10 patients on your transfemoral side and the first 10 patients on your transapical side, where do you think the curves would go?

Dr Bleiziffer. I did not try that, but I do not think that it would make much difference now with the larger patient numbers. 
Dr Bavaria. If you took out the first 10 patients from transapical and the first 10 patients from transfemoral and looked at those curves, do you think they would be basically the same as you have up there?

Dr Bleiziffer. I think so, yes.

Dr Bavaria. The second question has to do with your apical purse strings. There is a debate about whether box techniques versus purse-string techniques at the apex are the best. Which technique do you use for your apical suturing?

Dr Bleiziffer. We use two pledget-supported purse-string sutures.

Dr Khalid Rasheed (Islamabad, Pakistan). I congratulate you on this very elegant presentation regarding a challenging frontier. Regarding the potential complications of the transapical route, you have mentioned that there is an increased incidence of cardiac depression requiring various means of cardiopulmonary resuscitation and, second, the chance of producing an apical tear while closing the entry site. Inasmuch as the second complication is potentially fatal, what contingency arrangements do you have in place to deal with this catastrophic complication? Do you routinely prepare the femoral vessels to enable you to go on cardiopulmonary bypass to salvage the patient?

Dr Bleiziffer. We routinely place guide wires in the femoral artery and vein to facilitate the potential extracorporeal bypass installation.

Dr Rasheed. It is therefore an essential part of the protocol. Dr Bleiziffer. Yes, in all patients. 